\title{
EXPERIMENTAL STUDIES OF ACCELERATED CHLORIDE TRANSPORT IN CONCRETE
}

\author{
VOJTĚCH ZACHARDA*, JIŘÍ NĚMEČEK \\ Czech Technical University in Prague, Faculty of Civil Engineering, Thákurova 7, 16629 Prague 6, Czech \\ Republic \\ * corresponding author: vojtech.zacharda@fsv.cvut.cz
}

\begin{abstract}
This contribution deals with the efficiency of electromigration of chlorides used as a repair method for reinforced concrete structures. Experimental studies of accelerated chloride transport tests were performed on samples of concrete without chlorides and with admixed sodium chloride during concreting. Two concrete types from Portland cement characterized with normal and low compressive strengths were studied. The electromigration was applied to penetrate chlorides into the chloride-free sample and for extraction of chlorides from the sample. The effectiveness of the chloride extraction process for rehabilitation of reinforced concrete in terms of lowering the chloride concentration in different concrete types and surface concentration was observed. Electrical extraction was found to be effective for lowering of initial chloride concentration by $15-20 \%$ after 24 hours. The decrease in surface concentrations was found in the range of $40-50 \%$. The extraction process was found to be feasible and effective for both concrete types.
\end{abstract}

KEYWORDS: Concrete, electromigration, chlorides, extraction.

\section{INTRODUCTION}

Reinforced concrete structure is exposed to a variety of environmental processes during its lifetime that can cause degradation. The penetration of chlorides into the concrete from deicing salts or in sea splash areas are the most common deterioration processes. Chloride ions diffuse through concrete towards steel reinforcement and cause its corrosion. After reaching a critical value of chloride concentration on the rebar surface the corrosion of the steel starts $[1-3]$. The corrosion is accompanied by an expansion of the oxidic products causing high pressures, concrete cracking and finally spalling of a cover layer. Therefore, the resistance of concrete to penetration of chlorides is one of the very important properties for steel-reinforced concretes. Since the natural diffusion of ions [4, 5] is a slow process taking years further complicated by concrete aging and chloride binding [6] testing of concrete chloride permeability is often done in an accelerated manner using an electric field [7-9]. Both types of tests need to be properly interpreted and diffusion characteristics of concrete can be derived from the tests $[9,10]$.

Electrochemical extraction [7, 8] is one of the solutions that can be used to repair reinforced concrete structure already attacked by chlorides. Besides chlorides, other particles with the charge, such as corrosion inhibitors or nanoparticles, can also be transported via electric field [8, 11-13]. The convective flux of ions caused by the electromotive force is much larger that the diffusive flux and leads to radical shortening of the time needed for extraction of chlorides from the structure. In the reality, the electric field is realized between the steel reinforcement and the outer surface electrode (usually stainless steel mesh) placed on the concrete surface. In the lab scale, the tests are performed on concrete samples placed in between the mesh electrodes submerged in a suitable electrolyte. A standard test involves rapid chloride penetration [14] which categorizes samples into levels of vulnerability to the chloride attack. More precise measurements with chloride profile assessment will be presented in this paper.

\section{MATERIALS}

Two types of concrete mixtures were prepared for this study with low compressive strength (labeled as L) and with normal strength (labeled as N). Each type was prepared without chlorides and with $1 \%$ of cement weight $\mathrm{NaCl}$ addition to the mixture prepared from ordinary Portland cement CEM I-42,5R, sand and natural crushed aggregate. The mixtures composition is shown in the Table 1 The concrete was mixed in a 501 laboratory mixer for 10 minutes. The samples were cylindrical with height of $200 \mathrm{~mm}$ and diameter of $100 \mathrm{~mm}$. After casting they were vibrated for approximately 30 seconds. As prevention before water evaporation the specimens were covered with a foil. After 2 days after casting they were unmoulded and stored in water. The resulting 28-days compressive strengths and density of the L samples were $24.3 \mathrm{MPa}$ and $2216 \mathrm{~kg} / \mathrm{m}^{3}$ and $50.5 \mathrm{MPa}$ and $2340 \mathrm{~kg} / \mathrm{m}^{3}$ for $\mathrm{N}$ samples, respectively. For chloride penetration tests the specimens were cut to slices with the thickness of $50 \mathrm{~mm}$.

In this study the lower strength concrete represents a weak or damaged material that is worth to be repaired. The different content of cement also play a role 


\begin{tabular}{cccccccc}
\hline Type of concrete & $\begin{array}{c}\text { CEM I 42,5R } \\
{[\mathrm{kg}]}\end{array}$ & $\begin{array}{c}\text { Sand 0/4 } \\
{[\mathrm{kg}]}\end{array}$ & $\begin{array}{c}\text { Aggregate 4/8 } \\
{[\mathrm{kg}]}\end{array}$ & $\begin{array}{c}\text { Aggregate 8/16 } \\
{[\mathrm{kg}]}\end{array}$ & $\begin{array}{c}\text { Water } \\
{[\mathrm{kg}]}\end{array}$ & $\begin{array}{c}\mathrm{w} / \mathrm{c} \\
{[\mathrm{kgCl}]}\end{array}$ \\
\hline $\mathrm{N}$ & 436.4 & 872.7 & 290.9 & 581.8 & 186 & 0.43 & 0 \\
$\mathrm{~N}-1 \%$ & 436.4 & 872.7 & 290.9 & 581.8 & 186 & 0.43 & 4.36 \\
$\mathrm{~L}$ & 261.8 & 1150.0 & 290.9 & 581.8 & 210.2 & 0.8 & 0 \\
$\mathrm{~L}-1 \%$ & 261.8 & 1150.0 & 290.9 & 581.8 & 210.2 & 0.8 & 2.62 \\
\hline
\end{tabular}

TABLE 1. Concrete mixtures composition, mass per $1 \mathrm{~m}^{3}$.

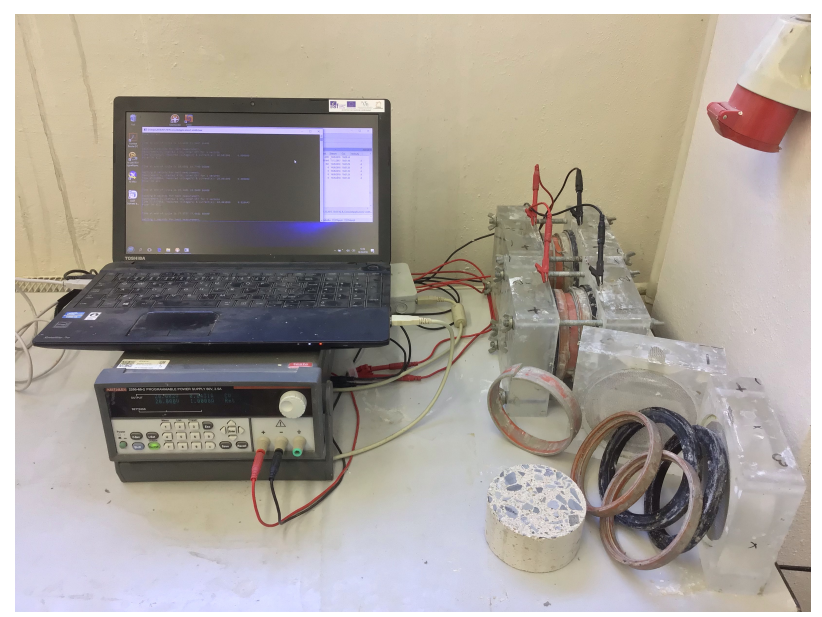

Figure 1. An electromigration setup used for accelerated chloride penetration/extraction tests.

in chloride binding that is higher in higher strength concrete.

\section{Methods}

In order to test the effectiveness of the electromigration process two types of accelerated tests were performed in an migration chamber. First, the chloride penetration test was made on the concrete samples without chlorides ( $\mathrm{N}$ and $\mathrm{L}$ series) and second, the accelerated chloride extraction test was performed on the samples with $1 \% \mathrm{NaCl}$ per cement addition (N-1\% and L-1\% series). The migration chamber composed of two containers with electrolyte solutions. In case of chloride penetration tests, a $3 \% \mathrm{NaCl}$ solution was used in the compartment with positive electrode and $0.3 \% \mathrm{NaOH}$ solution in the compartment with negative electrode. In case of chloride extraction, both compartments were filed with $0.3 \% \mathrm{NaOH}$ solution and chlorides driven into one of them. A DC power source with constant voltage of $20 \mathrm{~V}$ was connected to stainless steel mesh electrodes submerged in the electrolytes. The analyzed samples were inserted between the electrodes and the sample sealed (Fig. 1). The accelerated chloride penetration/extraction run for 24 hours. The scheme of tests is shown in Fig. 2 .

Before the tests of samples with $1 \%$ chloride addition, the original total chloride concentration was analyzed in $20 \mathrm{~mm}$ depth steps by drilling of the powder. Subsequently, the drilled holes were sealed in the samples and samples analyzed further. After the tests, the concentration was analyzed from powder collected in $5 \mathrm{~mm}$ depth steps. Always, the powder was mixed with extraction liquid based on potassium dichromate and acetic acid. After at least 24 hours, the solution was analyzed with $\mathrm{Cl}$ ion selective electrode and the chloride profile constructed.

\section{Results AND Discussion}

\subsection{Penetration of Chlorides}

The results of individual accelerated chloride penetration tests were used for calculation of average chloride concentration profile from 3-4 samples as shown in Fig. 3 for L samples and in Fig. 4 for $\mathrm{N}$ samples. The profile exhibits a gradual reduction of chlorides from surface of samples, which was exposed to the $3 \%$ $\mathrm{NaCl}$ solution. The shape of the profile is different in comparison with traditional diffusion tests. Here, the chlorides are driven by an electromotive force which is dominant and the profile is a "convective" one with the "middle bulge" caused by the convective force.

It can be seen in the figures that the surface concentration after 24 hours exposure is higher by $50 \%$ for $\mathrm{N}$ samples while the extent of the penetration, i.e. the penetration depth, is larger for $\mathrm{L}$ samples. Substantial chloride concentration appears within $40 \mathrm{~mm}$ of the $\mathrm{L}$ sample while only to $10 \mathrm{~mm}$ in the case of $\mathrm{N}$ sample. The difference in the surface concentration between $\mathrm{L}$ and $\mathrm{N}$ samples is related to the amount of cement in the mixture and the ability of the concrete to bind chlorides. The binding is higher for $\mathrm{N}$ samples which has twice as cement compared to L samples. The density of the $\mathrm{N}$ samples is however higher compared to L samples. Thus the permeability of the $\mathrm{N}$ samples is lower and the penetration depth is substantially lower compared to L samples.

\subsection{EXTRACTION OF CHLORIDES}

Original and after-the-extraction chloride concentration profiles are shown in Figs. 5 and 6 for L and $\mathrm{N}$ samples, respectively. Chlorides are extracted from the sample to the right compartment. The extraction causes decrease in concentration for both sample types. Most significantly, the concentration drops down in the surface region (left part of the profile in Figs. 5 and 6). The average decrease of chloride concentration was about $15 \%$ on L samples and $20 \%$ on N samples. The decrease in the surface region was more the $50 \%$ for L samples and about $40 \%$ for $\mathrm{N}$ samples. 


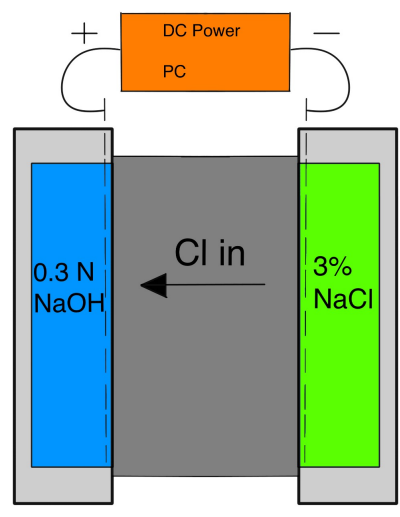

(A).

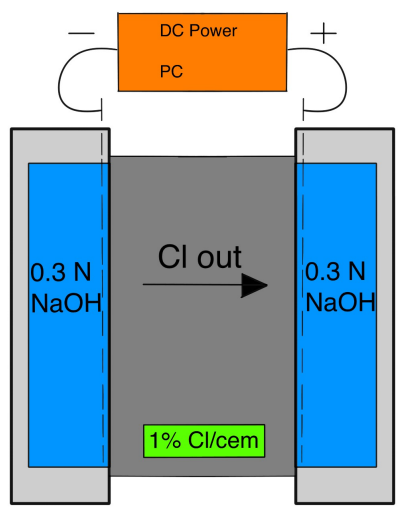

(в).

Figure 2. Scheme of accelerated chloride a) penetration test and b) extraction test.

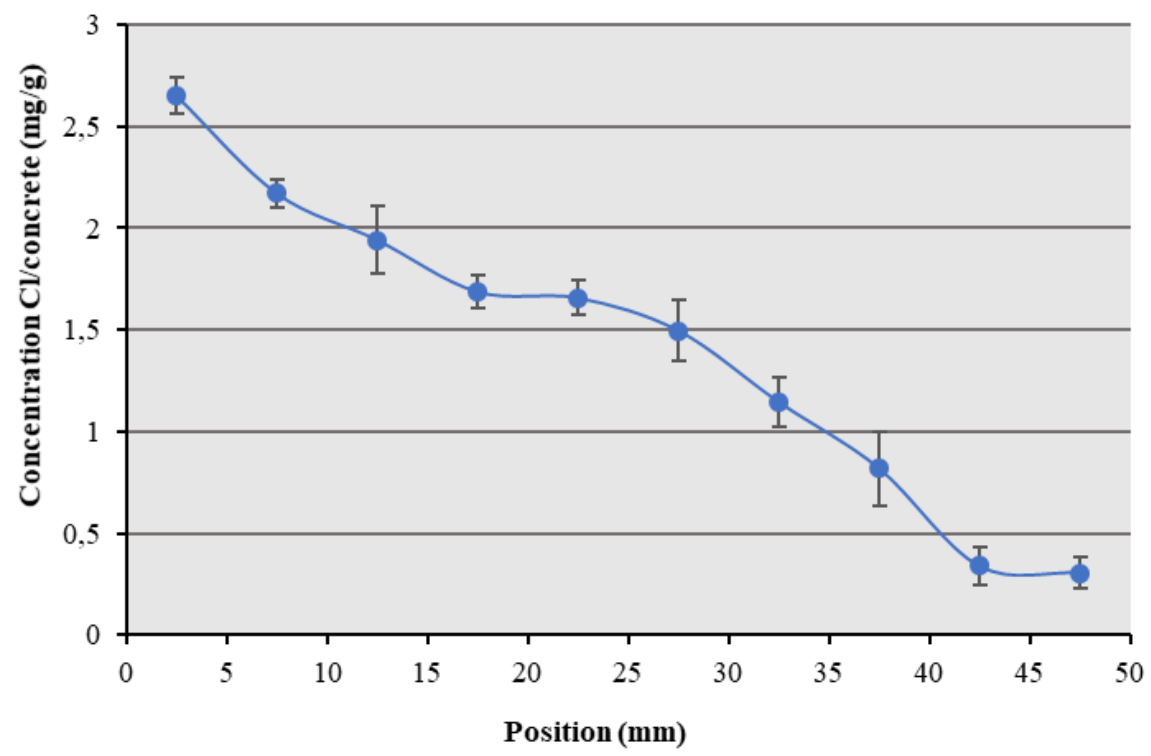

Figure 3. Concentration profile in L samples.

The profile is in agreement with the convective transport [10] which leads the chloride ions from left of the samples to the right compartment of the migration chamber. Note again, that the transport lasted for 24 hours with voltage of $20 \mathrm{~V}$. Further acceleration can be reached by using higher voltages or using larger times. Increasing voltage is, however, impractical due to safety reasons and due to Joule effect causing heating of the specimen. Increasing of the exposure time is, on the other hand, possible and higher efficiency leading to further lowering of the concentration would take place.

\section{Conclusions}

The presented paper provides results of accelerated chloride penetration and extraction tests performed on two typical concrete mixtures with different compositions with normal and low compressive strengths. The principle of electromigration was applied to penetrate chlorides into the chloride-free sample and to extract chlorides from the sample with some initial $\mathrm{Cl}$ concentration. The chloride profiles with concentrations that can be developed after long diffusion tests were gained here in 24 hours while applying safe voltage of $20 \mathrm{~V}$. The chloride concentrations were assessed from concrete core drills using an extraction liquid and ion selective electrode. Typical convective profiles with steep concentration change and different surface concentrations were obtained. The different permeability of the samples caused differences in both surface concentrations as well as in penetration depths. The surface concentration was twice as high in $\mathrm{N}$ samples compared to L samples. The penetration depth was three to four times larges in L samples compared to $\mathrm{N}$ samples. The first phenomenon can be attributed to a larger binding capacity of $\mathrm{N}$ samples given by 


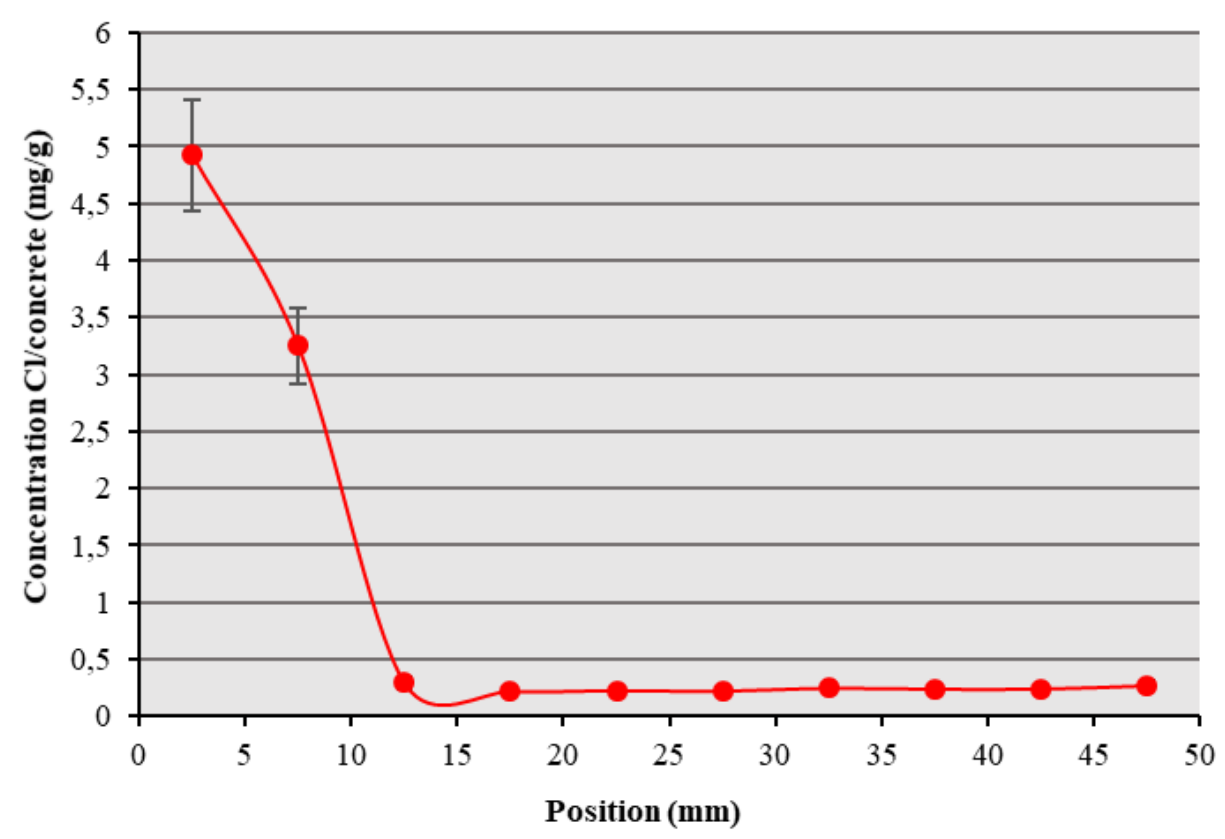

Figure 4. Concentration profile in $\mathrm{N}$ samples.

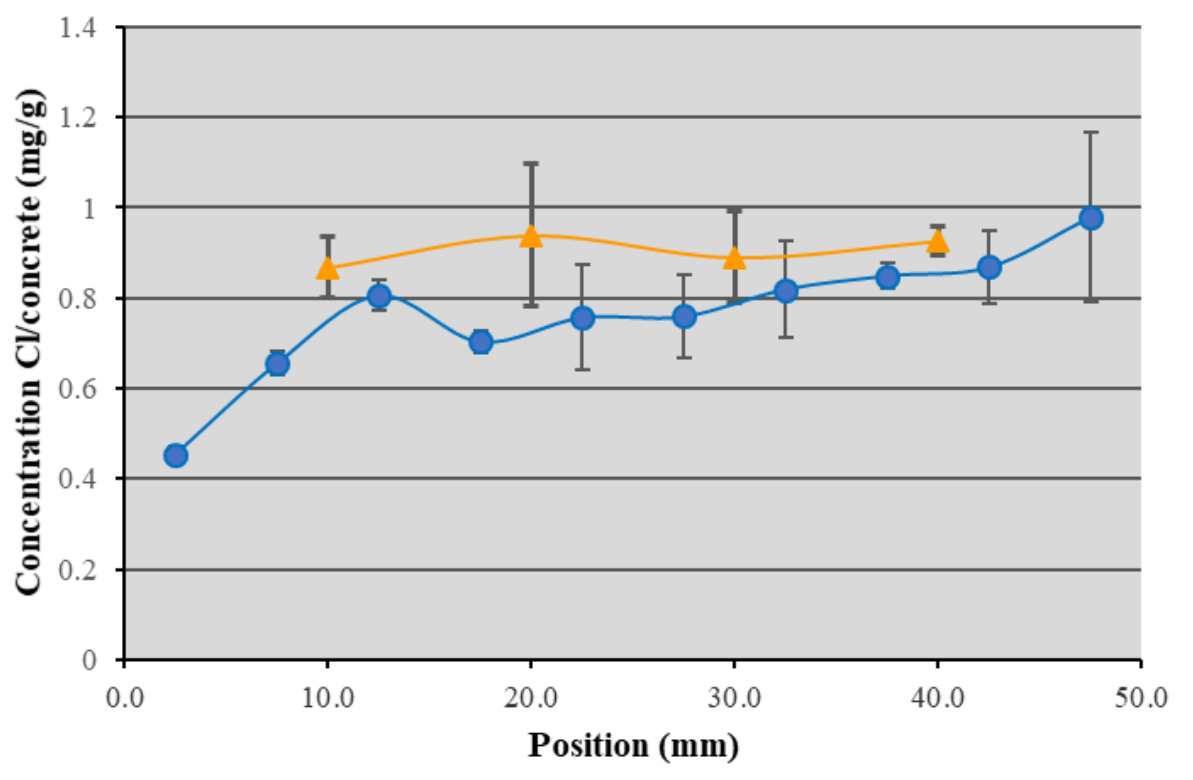

After extraction - - Orig. Conc.

Figure 5. Concentration profile of L-1\% samples before and after extraction. 


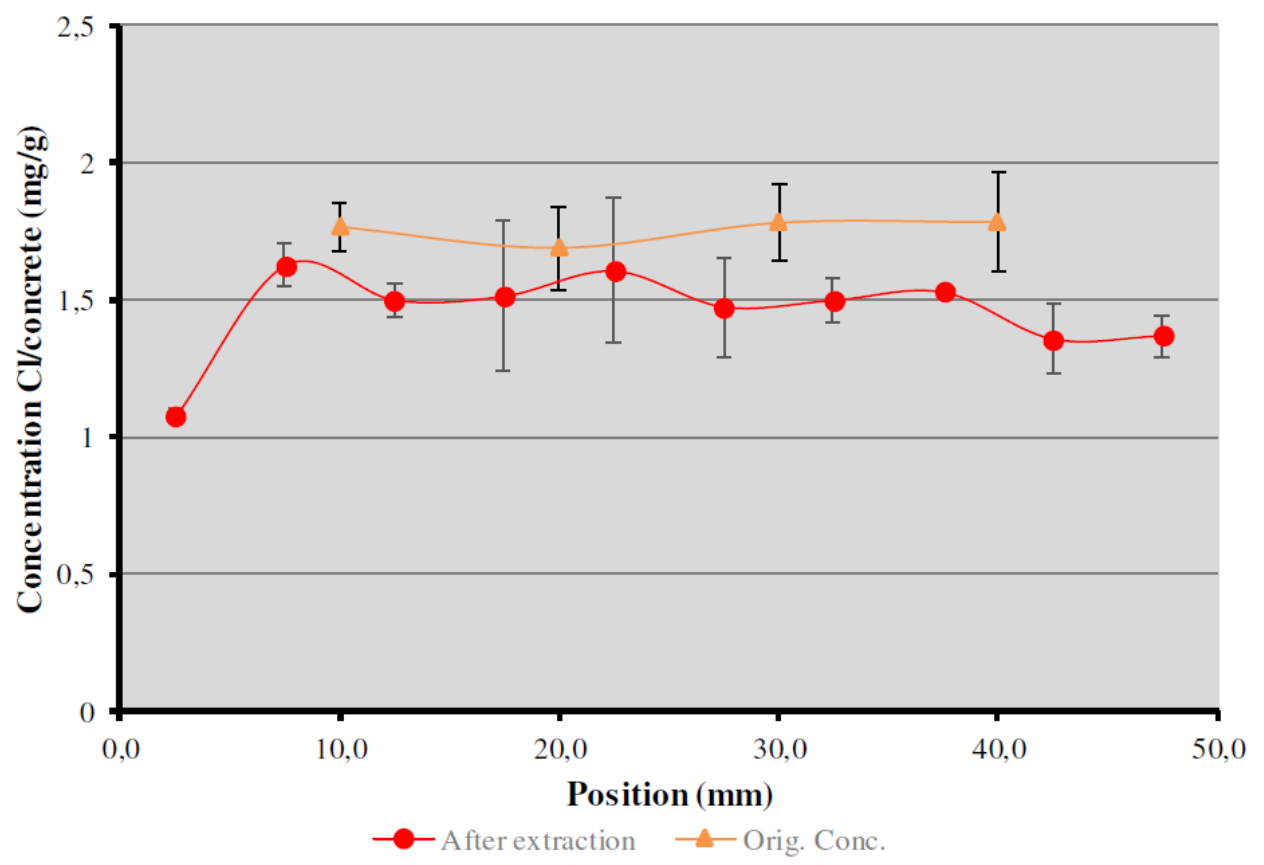

Figure 6. Concentration profile of N-1\% samples before and after extraction.

the twice amount of cement in comparison to L samples. Larger penetration depth in L samples is related to their increased permeability given by their lower density and higher porosity.

Electrical extraction was found to be an effective tool for lowering of initial chloride concentration. 15$20 \%$ average concentration decrease was reached after 24 hours. The decrease in surface concentrations was even higher (40-50\%) which corresponds to the convection of ions out of the samples. The extraction process was found to be feasible and effective for both concrete types.

\section{ACKNOWLEDGEMENTS}

Financial support of the Czech Science Foundation (project 16-11879S) and the Grant Agency of the Czech Technical University in Prague (SGS18/114/OHK1/2T/11) is gratefully acknowledged.

\section{REFERENCES}

[1] U. Angst, Ø. Vennesland. Critical chloride content in reinforced concrete - State of the art. In Alexander, et al. (eds.), Concrete Repair, Rehabilitation and Retrofitting II. Taylor and Francis Group, London, 2009.

[2] J. Cabrera. Deterioration of concrete due to reinforcement steel corrosion. Cement and Concrete Composites 18(1):47-59, 1996. DOI:10.1016/0958-9465(95)00043-7

[3] K. Tuutti. Corrosion of steel in concrete. Ph.D. thesis, Swedish Cement and Concrete Research Institute, Stockholm, 1982.

[4] C. Page, N. Short, A. El Tarras. Diffusion of chloride ions in hardened cement pastes. Cement and Concrete Research 11(3):395 - 406, 1981. DOI:10.1016/0008-8846(81)90111-3
[5] Y. Xi, Z. P. Bažant. Modeling chloride penetration in saturated concrete. Journal of Materials in Civil Engineering 11(1):58-65, 1999. DOI:10.1061/(ASCE)0899-1561(1999)11:1(58).

[6] Q. Yuan, C. Shi, G. De Schutter, et al. Chloride binding of cement-based materials subjected to external chloride environment - a review. Construction and Building Materials 23:1-13, 2009. DOI:10.1016/j.conbuildmat.2008.02.004

[7] M. Sánchez, C. Alonso. Electrochemical chloride removal in reinforced concrete structures: Improvement of effectiveness by simultaneous migration of calcium nitrite. Construction and Building Materials 25:873878, 2011. DOI:10.1016/j.conbuildmat.2010.06.099

[8] H. E. Cardenas, L. J. Struble. Electrokinetic nanoparticle treatment of hardened cement paste for reduction of permeability. Journal of Materials in Civil Engineering 18(4), 2006. DOI:10.1061/(ASCE)0899-1561(2006)18:4(554).

[9] P. Hlaváček, J. Němeček. Accelerated chloride migration tests in concrete. In Proceedings of 22nd International Conference Engineering Mechanics, pp. 213-216. 2016.

[10] J. Němeček, J. Kruis, T. Koudelka, T. Krejčí. Simulation of chloride migration in reinforced concrete. Applied Mathematics and Computation 319:575-585, 2018. DOI:10.1016/j.amc.2017.07.029.

[11] J. Němeček, Y. P. Xi. Nanoparticle injection into concrete using electromigration. In Special Concrete and Composites 2014, vol. 1054 of Advanced Materials Research, pp. 6-10. Trans Tech Publications, 2014. DOI:10.4028/www.scientific.net/AMR.1054.6.

[12] J. Němeček, L. Li, Y. Xi. Electrokinetic nanoparticle injection for remediating leaks in oil well cement. Construction and Building Materials 15:63-72, 2017. DOI:10.1016/j.conbuildmat.2017.08.152. 
[13] J. Němeček, R. Šulc, J. Němečková, J. Kruis. Nanoparticles in concrete: Application in fresh and hardened state. In Special Concrete and Composites 2017, vol. 760 of Key Engineering Materials, pp. 3-9. Trans Tech Publications, 2018.

DOI:10.4028/www.scientific.net/KEM.760.3
[14] ASTM C1202-19 - Standard Test Method for Electrical Indication of Concrete's Ability to Resist Chloride Ion Penetration. Standard, American Society for Testing and Materials, West Conshohocken. DOI:10.1520/C1202-19. 